\title{
Teachers' Experiences with Dyslexic Learners in Mainstream Classrooms: Implications for Teacher Education
}

\author{
S'lungile K Thwala ${ }^{1}$, Christian S. Ugwuanyi ${ }^{2}$, Chinedu I.O. Okeke ${ }^{2} \&$ Nombuso N. Gama $^{3}$ \\ ${ }^{1}$ Department of Educational Foundations \& Management, Faculty of Education, University of Eswatini, Kingdom of \\ Eswatini \\ ${ }^{2}$ School of Education Studies, Faculty of Education, University of the Free State, Bloemfontein, 9300, South Africa \\ ${ }^{3}$ Centre for International Technology College Mbabane, Kingdom of Eswatini \\ Correspondence: Christian S. Ugwuanyi, School of Education Studies, Faculty of Education, University of the Free \\ State, Bloemfontein, 9300, South Africa.
}

Received: August 1, 2020

Accepted: August 21, 2020

Online Published: August 25, 2020

doi:10.5430/ijhe.v9n6p34

URL: https://doi.org/10.5430/ijhe.v9n6p34

\begin{abstract}
Inclusive education represents the main ethos of the Kingdom of Eswatini education system. This reflects on both the constitution and on various education policies since the country became a signatory to the goals of Education for All. However, it would appear that major constraints impede the education vision that resonates through the charter of "no child is left behind'. The education of learners with dyslexia is then called into empirical questions with a focus on the experiences of teachers of such category of learners within the Eswatini education system. A phenomenological research design was chosen, using a convenience sampling technique to select 12 English language teachers of dyslexic learners. Data were obtained by individual semi-structured interviews and by non-participant observations. Content analysis was employed to analyze the data, which were then presented thematically. Peer review, as well as member checks, were used to improve the trustworthiness of data. The main themes that emerged were insufficient time, unwelcoming attitudes, lack of support, and lack of training of teachers of dyslexic learners. It was equally evident that teachers were challenged by insufficient training to enable them to deal with dyslexic learners. Without an effective support structure for teachers, the education of dyslexic learners would remain a chimera. This finding implicates the teacher education programmes in colleges of education and universities in the sense that training on inclusive classroom teaching should form part of the teacher education programme.
\end{abstract}

Keywords: dyslexic learners, mainstream classroom, teacher constraints, teacher education, unsupportive policy, Eswatini

\section{Introduction}

\subsection{Statement of the Problem}

Inclusive education is an education that ensures that learning takes place for both learners with special needs and learners without special needs. A key policy objective for the education of children and young people with special educational needs is an inclusive education (Lindsay, 2007). The policy of inclusive education stipulates equal learning opportunities for every child to enable them to attain their education and career fulfillment (Ahmad et al., 2018). Inclusive education is the kind of education that accommodates the needs of every learner in the society equitably irrespective of the state of their mental health (Leseyane et al., 2018). However, some children experience specific learning difficulties such as dyslexia concerning learning and that makes it harder for them to learn (Ahmad et al., 2018). Dyslexia is an unexpected difficulty in reading, and it has rapidly outpaced research (Worthy et al., 2016). Dyslexia is a persistent neurobiological disorder of genetic origin that affects academic performance (Prestes \& Feitosa, 2016).

According to Worthy et al. (2016), attention to dyslexia is evident in schools thus, the superintendent of one of the largest school districts in Texas pledged to approach dyslexia aggressively and proactively. Knight (2018) opined that teachers should understand what dyslexia is and its effects on their students because an estimated 5-10\% of the worldwide population of children is said to have dyslexia. It is estimated that $10 \%$ of the world's population has dyslexia or related learning difficulties which makes it imperative for teachers to have inclusive teaching techniques to take care of it (Indrarathne, 2019). Nijakowska (2019) reported teachers' poor level of preparedness to meet 
special educational needs and include dyslexic learners in mainstream classrooms. Thus, this study explored teachers' experiences with dyslexic learners in mainstream classrooms within the theoretical framework of Ajzen's (1988) Theory of Planned Behaviour (TPB).

\subsection{Theoretical Background of the Study}

Theory of Planned Behaviour by Ajzen (1988) assumes that asking people if they are intending to behave in a certain way is the best prediction of behaviour. This means that intention in behaviour will not express itself if it is physically impossible to perform the behaviour or if unexpected barriers stand in the way. According to Azjen, the determinants of behavioural intention are attitude, subjective norm and perceived behavioural control. Azjen believes that in model attitudes, subjective norms and perceived behavioural control predict the intention, which in turn predicts the behaviour. Besides, demographic factors determine the behaviour through the attitude, subjective norm, perceived behavioural control and intention. Thus, before the behaviour takes place, behavioural intention is explained by attitudes, subjective norms and perceived behavioural control. The researchers used this theory to explore the teachers' experiences with dyslexic learners in mainstream classrooms. Stampoltzis et al. (2018) used the theory and found that the teachers' intention towards teaching dyslexic pupils is predicted by the three determinants of behavioural intention.

\subsection{Review of Related Empirical Studies}

\subsubsection{Teachers' Experience with Dyslexic Learners}

Ahmad et al. (2018) revealed that the teaching of pupils with dyslexia poses a lot of challenges to teachers due to their lack of effective teaching methods in an inclusive classroom. Teachers held negative implicit attitudes toward challenging behavior and learning difficulties(Krischler \& Pit-ten Cate, 2019). Kormos and Nijakowska (2017) opined that pre- and in-service teachers tend to have concerns about children in an inclusive classroom. Pino and Mortari (2014) revealed significant gaps in the available stock of evidence on the inclusion of students with dyslexia in Higher Education. Knight (2018) revealed that teachers lacked the knowledge of the biological and cognitive aspects of learners with dyslexia and further demonstrated the relevance of good quality teacher training in increasing teachers' confidence working with such category of learners. Stampoltzis et al. (2018) observed that teachers faced several barriers and express neutral to positive attitudes to dyslexia.

Leseyane et al. (2018) revealed that teachers in public schools used negative comments that embarrassed dyslexic learners and offered no extra attention to them. English language teachers lack sufficient knowledge of the learning difficulties of learners with dyslexia as well as the inclusive language teaching practices (Indrarathne, 2019). Nijakowska (2014) as cited in Nijakowska (2019) found that the necessary knowledge and skills needed for inclusive teaching environments to meet the needs of dyslexic learners were lacking among foreign language teachers. There was a lack of necessary knowledge and skills to adjust the teaching approach towards dyslexics among English language teachers (Nijakowska et al., 2018). Considerable concerns and low levels of self-efficacy in implementing inclusive teaching practices with dyslexic learners were found among Foreign language teachers (Kormos \& Nijakowska, 2017). Keenan et al. (2020) found that teachers recognised their role in supporting the promotion of executive skills but reported that effective implementation of individualised supports for learners with dyslexia may be limited by issues with neuropsychological reports and resource limitations.

In Hong Kong, teachers are grappling with increasing diversity among learners, especially teaching learners with special educational needs (Chan \& Lo, 2017). School teachers faced substantial challenges in delivering quality instruction and helping children with dyslexia to overcome their difficulties in learning (Tam \& Leung, 2019). Teachers had more negative experiences than positive experiences in teaching learners with dyslexia (Yeo et al., 2016). Evidence from interviews with teachers of inclusive classrooms showed that there appeared to be an absence of teachers' strong leadership and ability in carrying out quality instruction in an inclusive classroom (Webster \& Blatchford, 2019). Teachers, most times, approach the inclusion of students with special education needs (SEN) in regular classrooms by feeling ill-prepared and apprehensive (Pit-ten Cate et al., 2018). Katsarou (2018) investigated teachers' views on inclusive education of children with dyslexia regarding Greek language and found a plethora of negative experiences among the teachers. A very limited number of elite schools provide policy to facilitate teachers' teaching in an inclusive classroom and no importance is paid to professional training related to dyslexia (Jaka, 2016). Thaver and Lim (2014) indicated that preservice teachers possessed negative attitudes towards people with disabilities due to little or no knowledge and experience with disability.

For the majority of teachers, the adequacy of initial teacher education to support struggling literacy learners in an inclusive classroom setting seems to have been low (Merga et al., 2020). Woodcock and Vialle (2016) indicated that 
teachers' attributional responses to learners with dyslexia were likely to have an unintended negative impact on students' self-efficacy and motivation to learning. Tiernan and Casserly (2018) found that teachers find it difficult to teach learners with dyslexia and thus recommended that effective additional teaching support literacy and numeracy could be provided in small groups to support the teaching of such learners. Dyslexic learners experience stigma related to their academic attainment and literacy due to the reflection of cultural norms in school practices and their fractured academic attainment is highly apparent during schooling (Lithari, 2019).

\subsubsection{Strategies for Helping Teachers Adapt in an Inclusive Classroom}

Teachers' training at both pre-service and in-service levels should emphasize training on special education (Thaver \& Lim, 2014). Knight (2018) revealed that evidence-based teacher training that updates teachers on the biological, cognitive and behavioural aspects of dyslexia is imperative to ensure that teachers have a more informed understanding of dyslexia (Nijakowska, 2019). To ensure literacy skills mastery among teachers of pupils with dyslexia, there is need for more support in terms of training and professional development (Ahmad et al., 2018). Nijakowska et al. (2018) highlighted the need for professional training for teachers of learners with dyslexia to enable them get used to the demands of inclusive classrooms. Stampoltzis et al. (2018) recommended that more positive teachers' attitudes and intentions will lead to more fruitful teacher-student interactions while barriers that stand between teachers and learners with dyslexia will be reduced.

Teacher training programmes on pedagogical competence is needed for the successful implementation of inclusive practice (Pit-ten Cate et al., 2018). As a strategy for assisting teachers of learners with dyslexia, Tiernan and Casserly (2018) opined that schools require further guidance and support in operationalizing resourcing models to effectively meet the needs of learners with dyslexia in an inclusive classroom. Merga et al. (2020) recommended that initial teacher education programmes and ongoing professional development opportunities should be properly implemented to ensure that such learning experiences are reflective of current teachers' needs in an inclusive classroom.

\subsection{Gaps in Literature}

Previous and recent studies in this area have focused on teachers' understanding and awareness of dyslexia (Worthy et nal., 2016) and quantitative research approach (Bell et al., 2011). Furthermore, Worthy et al. (2016) found that due to legislation and media attention, schools are under pressure to attend to dyslexia, but research provides few clear answers about instruction and most dyslexia research takes place outside teachers' perspectives. Besides, the review of empirical studies showed that despite that dyslexic learners face a lot of challenges in an inclusive classroom, little is known on the experience of teachers who teach in inclusive classrooms in the Kingdom of Eswatini education system. Thus, the researchers explored teachers' experiences with dyslexic learners in mainstream classrooms.

\subsection{Objectives of the Study}

1. Investigate teachers' perceptions of including learners with dyslexia in the mainstream set-up.

2. Ascertain the training skills teachers are exposed to, in handling learners with dyslexia in a regular classroom

\subsection{Research Questions}

1. What are teachers' perceptions of including learners with dyslexia in the mainstream set-up?

2. What are the training skills teachers are exposed to, in handling learners with dyslexia in a regular classroom?

\section{Methods}

\subsection{Research Paradigm, Approach and Design}

The researchers adopted interpretivism research paradigm for the study. The interpretivism paradigm has to do with the understanding of the world as it is from individual's subjective experiences. This kind of research paradigm uses interviewing or participant observation to obtain data necessary for a particular qualitative research. The study used a qualitative research approach. This is an approach that heavily relies on thick verbal descriptions of a particular social context being studied. It was suitable for the study as it intended to explore the teachers' experience in teaching dyslexic learners in mainstream classrooms. A phenomenological research design was adopted for this study. Phenomenology is powerful when the study's goal is to explore a concept loaded with social and cultural meanings especially when the topic does not render itself easily to quantification, and when new and fresh perspectives are needed. This design fits the study as it allowed the researchers to explore Swazi teachers' experiences in mainstreaming dyslexic learners. 


\subsection{Sample and Sampling Procedure}

The sample for this study was twelve (12) teacher participants which comprised one male and eleven (11) females. Schools that have learners with dyslexia were identified through the Ministry of Education. To select the schools, stratified random sampling, using a geographical category was used. The first and last schools in the categories of urban, semi-urban and rural schools were selected. Stratified random sampling fit in the study because schools in the Manzini region are divided into subsections of urban, semi-urban and rural schools, thus it allowed the representation of teachers from the different categories.

To select the teachers, the study used purposive sampling which involved selecting cases that met some predetermined criterion of importance. The teachers were included if they met the criteria of being English language teachers who had at least two years' experience teaching in an integrated classroom and they were currently teaching learners with dyslexia in primary school or they had experience teaching learners with dyslexia in a mainstream classroom. These criteria helped narrow down concentration to only mainstream teachers who had learners with dyslexia in their classrooms.

\subsection{Instruments and Data Trustworthiness}

Interview guide and observation schedule were used as instruments for data collection. Interviews are most appropriate where little is already known about the study phenomenon. The contents of the interview guide were on teachers' perceptions on including learners with dyslexia in the mainstream set-up as well as the training they receive in teaching such category of learners. The interview guide and the observation schedule were face validated by qualitative research experts to ensure that thy measure what they are meant to measure with respect to the study objectives for the sake of the credibility of the data collected. The interview guide was pilot tested on English teacher from the Hhohho region who also had dyslexic learners in her classrooms to ensure the trustworthiness of the data collected. This was done with the aim of determining if the questions were understandable and trustworthy. Also tested were the length of the interviews and the functionality of the recording device. Based on the results of the discussion, the guide was revised and questions that necessitated changing were reformed.

\subsection{Data Collection Procedures}

Four visits were made to the schools where the data were collected. The first visit was for asking for permission from the school principals and teachers to conduct the study. It also provided an opportunity for a preliminary meeting with the teachers which is an important step in a phenomenological study. The schedule for observations and interviews was also negotiated. During the second visit, there was initial observation and viewing of the various documents. The third visit was for interviews with the teachers concerned. The last visit was for a repeat of observations in each of the two classrooms where the prior interviewed teachers taught. Through participants' interviews, descriptive data were collected in the participant's own words so that researchers can gain insight into how participants interpret their world. Interviews were held in the teachers' respective classrooms in the various schools. This allowed for a quiet and undisturbed atmosphere where teachers freely expressed their views. The interviews ran for an average duration of 30-45 minutes.

Observations provided the researchers with an opportunity to record information as it occurs in a setting, to study actual behaviour and to study individuals who have difficulty verbalizing their ideas. The observation technique provided an opportunity for teachers to be observed as they interacted and taught dyslexic learners in their mainstream classrooms. An advantageous spot at the back in the classroom was sought and it served as a good viewing place of how the teachers interacted with the learners. Both descriptive and reflective field notes were taken as they allowed for the recording of the description of events, activities and people's reflections of what had occurred.

\subsection{Ethical Considerations}

The researchers ensured that ethical protocol was followed in conducting the study. The ethical clearance for the conduct of the study was obtained from the Ministry of Education. The researchers ensured that consent forms were given to the participants to sign for them to consent to be interviewed, observed and have their documents looked at. Confidentiality and anonymity of the participants' details were ensured by the researchers using pseudonyms. Interviews and observations were conducted as objectively and professionally as possible. Teachers were also notified from the onset that they were at liberty to drop off at any given point in time from the study and they were not going to be questioned about their withdrawal. 


\subsection{Data Analysis}

Data from the study were analysed using conventional content analysis. The conventional analysis allowed the researcher to gain a richer understanding of the phenomenon. In analyzing the qualitative data, the researchers had to clarify the themes and patterns to link concepts. The analysis of data obtained from the interviews, documents and observation was carried out through thematic qualitative data analysis. The raw data were organized, prepared, read thoroughly to make meaning of the responses of the participants.

\section{Results}

The results were presented based on the themes and subthemes that emerged during the data collection process.

\subsection{Theme 1: Insufficient Time}

The challenge that all participants seemed to share was that of insufficient time. This time challenge was reported to affect teaching/ learning on a continuum of school operations. It showed itself in different facets ranging from the syllabus, period allocation and average school time.

\subsubsection{Subtheme 1.1: Completing the Syllabus}

Teachers are expected by the administration and regional inspectors to have completed the syllabus by year-end as a sign that effective teaching had taken place. This means teachers are forced to rush through the syllabus if they are to complete it because failure to do so leads to them being taken to task and seen as incompetent. This, unfortunately, means in the process of rushing, dyslexic learners are often neglected because they need more attention which the teacher cannot give under the circumstances. Teachers are then forced to extend the time to after school or on Saturdays, which also does not come without its challenges. For example, a teacher lamented;

It's like a mother that is forced to sacrifice one of her children. While I understand that my dyslexic learners need time, it becomes painful because situations are beyond my control. I can't give them what they need, the time of the school calendar cannot allow me to give them due attention. (Female, 33 years old).

\subsection{Theme 2: Unwelcoming Attitudes}

Even though participants acknowledged that the inclusion of dyslexic learners had been mandated by the adoption of inclusive education in the country, most of them showed unwelcoming attitudes. While they accepted the move from the government towards inclusive education, most of them did not feel ready and prepared for such children.

\subsubsection{Subtheme 2.1: Negative Attitudes}

A barrier to the inclusion of dyslexic learners is that teachers perceived dyslexic learners as incapable. For most of the schools where this research was conducted, when the end of year results re discussed, dyslexic learners are made to repeat or are pushed to the next class if they have already repeated numerous times. This was under the perception that such a learner could not do much and is not expected to pass after all. For instance, a teacher commented;

They remain in the class until they eventually drop off or the system tires them out. It's now better with free education because the child can now repeat as much as he likes because he doesn't have to pay. Eventually, they drop off though. (Female, 14 years teaching experience)_

Some teachers felt that there was need to retain separate schools and have dyslexic learners attend there. This was because teachers felt drained by the need to put extra effort if they are to successfully include dyslexic learners. They perceived this inclusion as a challenge because it indirectly spelled out the need for them to stretch themselves as well. This was seen to contribute to the rejection of dyslexics. This was shown by the following assertion;

I hate it a little bit to have such learners. You see government doesn't pay me overtime yet if these learners are to pass, I have to take remedial work for them and sometimes sacrifice my afternoons for them. (Male, 36 years old).

Another teacher shared similar sentiments;

Dyslexic learners need to be fixed; it is challenging to have them in your class. They need their classes where they can find someone to help them according to their individual needs. (Female, 4 years teaching experience).

Such a perception, however, was seen to be subject to the severity of dyslexia and reflected the teachers' ability to include dyslexic learners in their teaching.

While not all teachers negatively perceived the inclusion of dyslexic learners in the mainstream, there was a consensus, however, that such learners were better off in special schools. This was because teachers felt that with the fast-paced system of mainstream schooling and the bulky syllabus, neglecting dyslexic learners was inevitable. This is elaborated in the following comments; 
I pity these children; they are better off in schools meant for them. (Female, 4 years teaching experience).

Another teacher had this to say;

Having sixty pupils in a single class is no child's play; it's impractical for me to be concentrating on struggling readers all the time. Special schools are better at that. (Female, 55 years old).

\subsubsection{Subtheme 2.2: Low Self-esteem}

The feeling of not accepting dyslexic learners in the mainstream was also seen to emanate from the observation that dyslexic learners are easily bruised in their self-esteem. Sometimes learners are offended if they are to remain behind for extra classes when their peers leave. Teachers expressed challenges that when convening dyslexic learners for remedial work, they often felt embarrassed to be separated from their peers. Such make the learners aware of their being 'different' and such feelings of being different affects their self-esteem negatively. Teachers thus felt confused about what best strategy to use because while they were sensitive to the dyslexic learners' self-esteem; there was a chance that such a leaner would fail if the self-esteem issue was given dominance. A teacher said;

Once they realize they have dyslexia, they withdraw from everyone. They feel like failures and I have to constantly help them participate in class. (Female, 39 years old).

\subsubsection{Subtheme 2.3: Powerlessness}

Some teachers perceived the inclusion of dyslexic learners as something they were powerless in fighting. They felt the government had imposed inclusive education on them and they had nothing else to do but to accept the situation as ${ }^{\wedge}$ was. Such a perception was not only confined to the inclusion of dyslexic learners, but teachers felt the whole advent of inclusive education as an imposed move. A female teacher commented;

It is sad because the government has made legislation and the only person between this controversy is the teacher. She has to make miracles without any support and equipment. (5 years of teaching experience).

\subsection{Theme 3: Lack of Support}

With inclusive education fully functional in Swaziland's primary schools, teachers of dyslexic learners were asked if they felt supported by the government and by their schools in mainstreaming learners. The responses pointed to the lack of governmental support.

\subsubsection{Subtheme 3.2: Governmental Support}

Teachers felt the need to have inspectors come to their schools for in-service training or call workshops where they would be trained on how to best help the dyslexic learners. Instead, the feeling was that the Ministry of Education concentrated on minor issues like checking official books instead of putting their energy in helping teachers understand their role in inclusive education.

For instance, it was said;

Our government does not provide enough reading materials and as a teacher, you have to make learners share. Teaching becomes impossible, learning becomes very difficult. (Female, 9 years teaching experience).

Another teacher commented;

Using NCC books is a challenge because they are not rich and helpful to struggling readers. I'm forced to supplement with such reading books as Ladybird Series. (Female, 51 years old).

\subsubsection{Subtheme 3.2: Administrative Support}

In Swaziland, the government is the main regulatory body in the education system. Principals are entrusted with the day to day running of the school and they have the power to make certain decisions about the functioning of the school. It was thus investigated whether schools did support teachers of learners with dyslexia in their teaching of dyslexic learners. Teachers were asked to comment on how their schools fared in supporting their teaching. While some teachers felt supported by their schools, others felt, like the government, that their schools were failing them.

For instance, one teacher commented;

The administration doesn't help us in any way. They feel children are never failures, it's instead the teacher who fails. So, I end up not asking for help because I will be blamed instead. (Female, 5 years teaching experience).

The lack of school support was also seen in that resources for issues that had to do with the buying of supplementary reading materials were not given priority. With the introduction of free primary education, all financial aid comes from the government. This provides a challenge in that sometimes it takes longer for the government to release the 
money to schools such that by the time resources arrive, the school is already in debt. This money is then used to repay the debts and as a result, little is spared to help provide reading material requested by teachers. Apart from the money arriving late in schools, it is often not enough. This creates a situation where some needs that are not crucial are ignored for the most immediate school needs.

\subsection{Theme 4: Lack of Training}

Six of the teachers were not exposed to any form of tertiary training or in-service training on either inclusive education or dyslexia. Even though there were a variety of teachers ranging from those trained in inclusive education, partially trained and not trained, there was very little, or no difference observed in their ability to include dyslexic learners. The majority admitted to struggling to successfully include dyslexic learners in their mainstream classrooms.

\subsubsection{Subtheme 4.1: Pre-service Training}

It was reported that most of the teachers who teach in an inclusive classroom were not trained on inclusive education. This made them to have unpleasant experiences handling dyslexic learners. They shared unanimous sentiments that their training was not enough. For instance:

Learning disabilities were only hinted about in my training, they never went into detail. I'm as good as someone who never did anything on inclusive education. (Male, 6 years teaching experience).

Another teacher held similar sentiments when she said:

Dyslexia was highlighted in my training. Despite this training, I do not feel adequately prepared to teach dyslexics because my training looked at inclusive education as an umbrella course and not much time or vigor was invested in dyslexia as a single entity. (Female, 5 years teaching experience).

Even though one teacher was confident in her training, she felt without cooperation from other teachers, she could not successfully include dyslexic learners. The lack of training and knowledge on the part of other teachers made things hard because teaching is a joint effort. She had this to say;

For learners to progress from the previous grade; another teacher has to help them through. It's hard for me to make dyslexic learners unlearn some of the perceptions they have formed over the years about themselves. It's this very uninformed perception that hinders dyslexic learners' ability to successfully perform in class (Female, 9 years of teaching experience).

\subsubsection{Subtheme 4.2: In-service Training}

The participants reported that there was no form of in-service training on inclusive education for them. According to them, the inspectors, instead of carrying out in-service training for them, visited them for such things as official books where they were interested in assessing if these were up to date. This is what one teacher had to say:

We need them to be talking about these important things like disabilities instead of all the time they tell us about the need to have updated scheme books. (Female, 5 years teaching experience).

Of the 12 teachers, three talked about how they, over the years, benefited from workshops that touched on how to help learners read. They felt if such workshops were followed up on maybe yearly basis, they would be of benefit to teachers. Even though such workshops were not on dyslexia, they helped teachers understand practically how to help prevent reading problems.

\subsubsection{Subtheme 4.3: Individualized Education Programme}

It was ascertained that there was no IEP in mainstream schools in Swaziland. This posed a great challenge for teachers in that with most of them having admitted to lack knowledge about dyslexia, tailor-making lessons according to individual learner needs were thus almost impossible. Teachers showed a lack of knowledge of what the IEP was and what they were expected to do when designing one. Instead, a general lesson plan was used in the classrooms.

\section{Discussions}

The findings of the study revealed that teachers of dyslexic learners had unpleasant experiences with the teaching of such category of learners in mainstream classrooms in the Eswatini education system. They felt these learners were in the wrong place and mainstream education was not benefiting them. Teachers had a general feeling that dyslexics required a lot of effort from the teacher and they needed extra time for remediation, which was challenging to find in mainstream set-ups. This feeling of rejection for dyslexics was not restricted to them alone but also to learners with 
intellectual disabilities. Teachers accepted learners with physical disabilities but had challenges accepting the latter. This may be attributed to the fact that the teachers who participated in the study reported a low level of training in inclusive education. Buttressing these findings are the findings of similar studies across the globe.

Leseyane et al. (2018) revealed that teachers in public schools were not patient with dyslexic learners but used negative comments that embarrassed them and offered no extra attention to them. English language teachers lack sufficient knowledge on the learning difficulties of learners with dyslexia as well as the inclusive language teaching practices (Indrarathne, 2019). Nijakowska (2014) as cited in Nijakowska (2019) found that foreign language teachers lack the necessary knowledge and skills to appropriately create inclusive teaching environments to meet the needs of dyslexic learners. English language teachers often lack the necessary knowledge and skills to adjust their teaching approach towards dyslexics (Nijakowska et al., 2018). Foreign language teachers tend to have considerable concerns and demonstrate rather low levels of self-efficacy in implementing inclusive teaching practices with dyslexic learners (Kormos \& Nijakowska, 2017). Keenan et al. (2020) found that teachers recognised their role in supporting the promotion of executive skills but reported that effective implementation of individualized supports for learners with dyslexia may be limited by issues with neuropsychological reports and resource limitations.

School teachers faced substantial challenges in delivering quality instruction and helping children with dyslexia to overcome their difficulties in learning (Tam \& Leung, 2019). Teachers had more negative experiences than positive experiences in teaching learners with dyslexia (Yeo et al., 2016). Teachers' most dominant negative experience was stress from challenging behaviour and instructional difficulties associated with the teaching of learners in an inclusive classroom (Yeo et al., 2016). Evidence from interviews with teachers of inclusive classrooms showed that there appeared to be an absence of teachers' strong leadership and ability in carrying out quality instruction in an inclusive classroom (Webster \& Blatchford, 2019). Teachers, most times approach the inclusion of students with special education needs (SEN) in regular classrooms by feeling ill-prepared and apprehensive (Pit-ten Cate et al., 2018). Katsarou (2018) investigated teachers' views on inclusive education of children with dyslexia regarding Greek language and found a plethora of negative experiences among the teachers. Few elite schools provide a policy to facilitate teachers' teaching in mainstream education and no importance is paid to professional training related to dyslexia and as a result, children with dyslexia face many emotional and academic problems (Jaka, 2016).

\subsection{Implications for Teacher Education}

The above findings have serious implications for teacher education. Since the teachers of dyslexic learners have great challenges in the teaching of such learners, there is need for a paradigm shift in the teacher education programme. The teacher education programme needs to be transformed in such a way that it includes training in inclusive education for teachers. Teachers' training at both pre-service and in-service levels should emphasize training on special education (Thaver \& Lim, 2014). Knight (2018) revealed that evidence-based teacher training that updates teachers on the biological, cognitive and behavioural aspects of dyslexia, is imperative to ensure that teachers have a more informed understanding of dyslexia (Nijakowska, 2019). To ensure literacy skills mastery among teachers of pupils with dyslexia, there is need for more support in terms of training and professional development (Ahmad et al., 2018).

Nijakowska et al. (2018) highlighted the need for professional training of teachers of learners with dyslexia to enable them to get used to the demands of inclusive classrooms. Stampoltzis et al. (2018) recommended that more positive teachers' attitudes and intentions will lead to more fruitful teacher-student interactions while barriers that stand between teachers and learners with dyslexia will be reduced. Teacher training programmes on pedagogical competence is needed for the successful implementation of inclusive practice (Pit-ten Cate et al., 2018). For majority of the teachers, the adequacy of initial teacher education to support struggling literacy learners in an inclusive classroom setting seems to have been low (Merga et al., 2020).

\subsection{Conclusion and Recommendations}

The results revealed that though the general perception was not outright rejection, there were a lot of salient negative attitudes that teachers had towards dyslexic learners being in mainstream classrooms. The teachers who participated in the study reported a very low level of training in inclusive education. Though teachers had teacher training certificates, diplomas and degrees, only one was trained in inclusive education. Even though the five other teachers had received an introductory course in inclusive education, it was not enough to foster confidence in their abilities to successfully include learners with special needs. The teachers' way of thinking also reflected vague ideas about inclusion. For instance, their training was not enough to enable them to simultaneously offer remedial work to dyslexic learners in the very learning time alongside their peers, not separately. Based on the findings of the study, the following recommendations are made: 
- While it may be tempting for teachers to concentrate on the negative aspects of dyslexic learners, a paradigm shift to look for strengths that dyslexic learners exude and not just view them negatively is necessary. This would greatly help the learners in the development of a positive self-concept

- Since it has been ascertained that mainstream primary school teachers lack the pre-requisite training for including dyslexic learners in mainstream contexts, there is need for teachers to be subjected to in-service training on inclusive education.

- Teachers also need to receive training on how to write individualised education programmes (IEPs). The government can aid by deploying the inspectorate to run workshops on how to design IEP's.

Adequate training is also needed to enable teachers to be in a good position to make differentiated instruction. Teachers need training on how to tailor-make instruction to allow learners to grow and achieve.

\section{Acknowledgments}

The researchers appreciate all the study participants as well as the principals of the schools used for the investigation for their cooperation through the period of the data collection.

\section{Authors' ORCiD}

S'lungile K Thwala https://orcid.org/0000-0002-7844-1514

Christian S. Ugwuanyi https://orcid.org/0000-0003-2174-3674

Chinedu I.O. Okeke https://orcid.org/0000-0003-3046-5266

\section{References}

Ahmad, S., Ali, M. M., \& Salehuddin, K. (2018). ESL Teachers' Experience in Teaching Pupils with Dyslexia in Mainstream Classrooms. Creative Education, 09(14), 2171-2182. https://doi.org/10.4236/ce.2018.914158

Ajzen, I. (1988). Attitudes, personality and behaviour. Milton Keynes; OUP.

Bell, S., Mcphillips, T., \& Doveston, M. (2011). How do teachers in Ireland and England conceptualise dyslexia? Journal of Research in Reading, 34(2), 171-192. https://doi.org/10.1111/j.1467-9817.2009.01419.x

Chan, C., \& Lo, M. (2017). Exploring inclusive pedagogical practices in Hong Kong primary EFL classrooms. International Journal of Inclusive Education, 21(7), 714-729. https://doi.org/10.1080/13603116.2016.1252798

Indrarathne, B. (2019). Accommodating Learners With Dyslexia in English Language Teaching in Sri Lanka: Teachers' Knowledge, Attitudes, and Challenges. TESOL Quarterly, 53(3), 630-654. https://doi.org/10.1002/tesq.500

Jaka, F. S. (2016). Head Teachers and Teachers as Pioneers in Facilitating Dyslexic Children in Primary Mainstream Schools. Journal of Education and Educational Development, 2(2), 172. https://doi.org/10.22555/joeed.v2i2.445

Katsarou, D. (2018). Teachers' Views On Inclusive Education Of Children With Dyslexia Regarding Greek Language: A Pilot Study. European Journal of Education Studies, 34(19), 122-128. https://doi.org/10.5281/zenodo.1406047

Keenan, L., O’Sullivan, A., \& Downes, M. (2020). Teachers' experiences and understanding of executive functions in Irish primary school classrooms: Findings from a mixed-methods questionnaire. Irish Educational Studies, $O(0), 1-14$. https://doi.org/10.1080/03323315.2020.1794927

Knight, C. (2018). What is dyslexia? An exploration of the relationship between teachers' understandings of dyslexia and their training experiences. Dyslexia, 24(3), 207-219. https://doi.org/10.1002/dys.1593

Kormos, J., \& Nijakowska, J. (2017). Inclusive practices in teaching students with dyslexia: Second language teachers' concerns, attitudes and self-efficacy beliefs on a massive open online learning course. Teaching and Teacher Education, 68, 30-41. https://doi.org/10.1016/j.tate.2017.08.005

Krischler, M., \& Pit-ten Cate, I. M. (2019). Pre- and in-service teachers' attitudes toward students with learning difficulties and challenging behavior. Frontiers in Psychology, 10(FEB), 1-10. https://doi.org/10.3389/fpsyg.2019.00327

Leseyane, M., Mandende, P., Makgato, M., \& Cekiso, M. (2018). Dyslexic learners' experiences with their peers and teachers in special and mainstream primary schools in North-West Province. African Journal of Disability, 7 , 1-7. https://doi.org/10.4102/ajod.v7i0.363

Lindsay, G. (2007). Educational psychology and the effectiveness of inclusive education/mainstreaming. British 
Journal of Educational Psychology, 77(1), 1-24. https://doi.org/10.1348/000709906X156881

Lithari, E. (2019). Fractured academic identities: dyslexia, secondary education, self-esteem and school experiences. International Journal of Inclusive Education, 23(3), 280-296. https://doi.org/10.1080/13603116.2018.1433242

Merga, M. K., Mat Roni, S., \& Mason, S. (2020). Teachers' perceptions of their preparedness for supporting struggling literacy learners in secondary English classrooms. English in Education, 00(00), 1-20. https://doi.org/10.1080/04250494.2020.1775488

Nijakowska, J. (2019). Foreign language teachers' preparedness to cater for special educational needs of learners with dyslexia: a conceptual framework. European Journal of Special Needs Education, 34(2), 189-203. https://doi.org/10.1080/08856257.2019.1581401

Nijakowska, J., Tsagari, D., \& Spanoudis, G. (2018). English as a foreign language teacher training needs and perceived preparedness to include dyslexic learners: The case of Greece, Cyprus, and Poland. Dyslexia, 24(4), 357-379. https://doi.org/10.1002/dys.1598

Pino, M., \& Mortari, L. (2014). The inclusion of students with dyslexia in higher education: A systematic review using narrative synthesis. Dyslexia, 20(4), 346-369. https://doi.org/10.1002/dys.1484

Pit-ten Cate, I., Markova, M., Krischler, M., \& Krolak-Schwerdt, S. (2018). Promoting Inclusive Education: The Role of Teachers' Competence and Attitudes. Insights into Learning Disabilities, 15(1), 49-63.

Prestes, M. R. D., \& Feitosa, M. A. G. (2016). Teorias da dislexia: Sustentação com base nas alterações perceptuais auditivas $=$ Theories of dyslexia: Support by changes in auditory perception. Psicologia: Teoria e Pesquisa, 32(5), 1-9.

http://proxy.libraries.smu.edu/login?url=http://search.ebscohost.com/login.aspx?direct=true\&db=psyh\&AN=20 17-35603-019\&site=ehost-live \&scope=site\%0Aprestes.marta3@gmail.com https://doi.org/10.1590/0102-3772e32ne24

Stampoltzis, A., Tsitsou, E., \& Papachristopoulos, G. (2018). Attitudes and intentions of Greek teachers towards teaching pupils with dyslexia: An application of the theory of planned behaviour. Dyslexia, 24(2), 128-139. https://doi.org/10.1002/dys. 1586

Tam, I. O. L., \& Leung, C. (2019). Evaluation of the effectiveness of a literacy intervention programme on enhancing learning outcomes for secondary students with dyslexia in Hong Kong. Dyslexia, May, 1-22. https://doi.org/10.1002/dys.1626

Thaver, T., \& Lim, L. (2014). Attitudes of pre-service mainstream teachers in Singapore towards people with disabilities and inclusive education. International Journal of Inclusive Education, 18(10), 1038-1052. https://doi.org/10.1080/13603116.2012.693399

Tiernan, B., \& Casserly, A. M. (2018). The impact and the implications of policy regarding the organisation of support for pupils with dyslexia in Irish primary mainstream schools. Irish Educational Studies, 37(1), 51-67. https://doi.org/10.1080/03323315.2017.1421089

Webster, R., \& Blatchford, P. (2019). Making sense of 'teaching', 'support' and 'differentiation': the educational experiences of pupils with Education, Health and Care Plans and Statements in mainstream secondary schools. European Journal of Special Needs Education, 34(1), 98-113. https://doi.org/10.1080/08856257.2018.1458474

Woodcock, S., \& Vialle, W. (2016). An examination of pre-service teachers' attributions for students with specific learning difficulties. Learning and Individual Differences, 45, 252-259. https://doi.org/10.1016/j.lindif.2015.12.021

Worthy, J., DeJulio, S., Svrcek, N., Villarreal, D. A., Derbyshire, C., LeeKeenan, K., Wiebe, M. T., Lammert, C., Rubin, J. C., \& Salmerón, C. (2016). Teachers' Understandings, Perspectives, and Experiences of Dyslexia. Literacy Research: Theory, Method, and Practice, 65(1), 436-453. https://doi.org/10.1177/2381336916661529

Yeo, L. S., Chong, W. H., Neihart, M. F., \& Huan, V. S. (2016). Teachers' experience with inclusive education in Singapore. Asia Pacific Journal of Education, 36(0), 69-83. https://doi.org/10.1080/02188791.2014.934781

\section{Copyrights}

Copyright for this article is retained by the author(s), with first publication rights granted to the journal.

This is an open-access article distributed under the terms and conditions of the Creative Commons Attribution license (http://creativecommons.org/licenses/by/4.0/). 